Proceedings of the 35th Annual Meeting of the European Embryo Transfer Association (AETE); Murcia, Spain, September 12th and 14th, 2019.

\title{
Intrafollicular barriers and cellular interactions during ovarian follicle development
}

\section{Gabriella Mamede Andrade, Maite del Collado, Flávio Vieira Meirelles, Juliano Coelho da Silveira, Felipe Perecin*}

${ }^{1}$ Faculty of Animal Sciences and Food Engineering, Department of Veterinary Medicine, University of São Paulo, Pirassununga, São Paulo, Brazil.

\section{Abstract}

Follicles are composed of different interdependent cell types including oocytes, cumulus, granulosa, and theca cells. Follicular cells and oocytes exchange signaling molecules from the beginning of the development of the primordial follicles until the moment of ovulation. The follicular structure transforms during folliculogenesis; barriers form between the germ and the somatic follicular cells, and between the somatic follicular cells. As such, communication systems need to adapt to maintain the exchange of signaling molecules. Two critical barriers are established at different stages of development: the zona pellucida, separating the oocyte and the cumulus cells limiting the communication through specific connections, and the antrum, separating subpopulations of follicular cells. In both situations, communication is maintained either by the development of specialized connections as transzonal projections or by paracrine signaling and trafficking of extracellular vesicles through the follicular fluid. The bidirectional communication between the oocytes and the follicle cells is vital for driving folliculogenesis and oogenesis. These communication systems are associated with essential functions related to follicular development, oocyte competence, and embryonic quality. Here, we discuss the formation of the zona pellucida and antrum during folliculogenesis, and their importance in follicle and oocyte development. Moreover, this review discusses the current knowledge on the cellular mechanisms such as the movement of molecules via transzonal projections, and the exchange of extracellular vesicles by follicular cells to overcome these barriers to support female gamete development. Finally, we highlight the undiscovered aspects related to intrafollicular communication among the germ and somatic cells, and between the somatic follicular cells and give our perspective on manipulating the above-mentioned cellular communication to improve reproductive technologies.

Keywords: cellular communication, extracellular vesicles, granulosa cells, oocyte, ovarian follicle, transzonal projections

\section{Introduction: Follicle development}

The ovarian follicle development starts long before birth during the intra-uterine period (Russe, 1983). The primordial germ cells migrate to the genital ridge, colonize, and proliferate. After this highly proliferative period, a human female fetus has approximately 6-7 million germ cells around the $20^{\text {th }}$ week of gestation, however a vast majority of these germ cells are lost and approximately 1 to 2 million oocytes remain viable at birth (Motta et al., 1997; Sun et al., 2017). In bovines, the maximum number of germ cells is around 2.5 million at about the $15^{\text {th }}$ week of gestation (Erickson, 1966) and thirteen days after birth bovine germ cells number decrease approximately to 68 thousand. This dramatic loss of germ cells close after birth occurs in most female mammals (Paulini et al., 2014).

Once mitotic proliferation stops, these germ cells arrest at meiotic prophase I to form the germ cell nests (Buehr, 1997; Tilly, 2001; Sun et al., 2017). Close to birth, breakdown of the germ cell nests occurs with the formation of the primordial follicle. Two cell types characterize this primordial follicle: a primary oocyte surrounded by a single layer of pre-granulosa cells (Fortune, 1994; BrawTal and Yossefi, 1997; Eppig, 2001). The primordial follicle population in the ovary serves as a reservoir for developing follicles and oocytes throughout the female reproductive life (Zuckerman, 1951; Kerr et al., 2013). After puberty, groups of primordial follicles are periodically recruited to initiate folliculogenesis.

Although the precise mechanisms that regulate germline nest breakdown and primordial follicle formation are mostly unknown (Wang et al., 2017), several growth factors and hormones play essential roles in primordial follicle formation (Pepling, 2012), for example estradiol-17 $\beta$ (E2) and members of the transforming growth factor beta (TGF- $\beta$ ) superfamily (Knight and Glister, 2006; Wang and Roy, 2007; Chakraborty and Roy, 2017). The TGF- $\beta$ family members are secreted by the oocyte and include bone morphogenetic protein 15 (BMP15) and growth differentiation factor 9 (GDF9), which act via autocrine and paracrine mechanisms, regulating follicle growth and differentiation, as well as granulosa and thecal cell function during follicular development (Dong et al., 1996; Eppig et al., 1997; Gilchrist et al., 2004; Sanfins et al., 2018). By secreting these members of TGF- $\beta$ family the oocyte is the main responsible for activating primordial follicles (Eppig, 2001).

Ovarian follicle development is a continuous process that has two different phases: the preantral and antral. The first phase, preantral, is gonadotropinindependent and relies on local growth factors. As folliculogenesis progresses, the follicle becomes 
gonadotropin-responsive and develops until secondary follicles. The second phase, antral, is gonadotropindependent and is characterized by the presence of the tertiary follicles, which has the presence the antrum, a cavity filled with follicular fluid (Dvorrák and Tesařík, 1980; Erickson and Shumichi, 2001). This entire process of growth and differentiation of the follicle is accompanied by the oocyte growth and acquisition of competence (El-Hayek and Clarke, 2015; Monniaux, 2016).

Stimulation by the locally secreted factors activates the primordial follicles initiating the preantral growth phase for development into a primary follicle. Factors responsible for primary follicle development are not fully known; however, it is known that granulosa cell-derived anti-Mullerian hormone and activins participate in the regulation of this process (reviewed by Matzuk et al., 2002). The primary follicles are characterized by the presence of an oocyte covered with a single layer of cuboidal granulosa cells. As the oocyte grows, the granulosa cells proliferate to envelop the surface of the expanding oocyte (vandenHurk et al., 1997).

Continuous granulosa cell proliferation results in multiple layers of cells surrounding the oocyte and the follicles are referred to as secondary follicles. At this stage, the formation of the theca cell layer starts, separated from the granulosa by a basement membrane (BrawTal and Yossefi, 1997). At the same time, oocytes undergo alterations as the formation of cortical granules in the cytoplasm (Fair et al., 1997) and the beginning of mRNA synthesis (McLaughlin et al., 2010). At this stage, the formation of the zona pellucida (ZP) around the oocyte starts, to form the first significant barrier between the oocyte and the somatic granulosa cells (BrawTal and Yossefi, 1997; Clarke, 2018) (Fig. 1A).

As the secondary follicle develops, more layers of granulosa cells form, and an antral cavity filled with follicular fluid develops between them. With the initiation of the antral phase of follicular growth, the follicle is now a tertiary follicle. During the transition of the secondary to tertiary follicle the second significant barrier between follicular cells is formed (Fig. 1B). Indeed, the antrum induces the differentiation of granulosa subpopulations, the original granulosa cells present in the outer wall of the follicle and that specialized granulosa cells, now cumulus cells, that directly surround the oocyte during further development. Mural granulosa cells and cumulus cells became exposed to opposing gradients of folliclestimulated hormone (FSH) and oocyte-secreted factors (OSF) (Fortune, 1994; Eppig, 2001; Wigglesworth et al., 2015). In this phase of intense follicle growth, the oocyte slows down or even stops its growth, while stromal cells form two layers of cells external to the basement membrane, the internal and external theca cell layers (Fair et al., 1997; Hyttel et al., 1997; Guo et al., 2016).

In bovine, from the beginning of antral phase until a diameter of approximately $8 \mathrm{~mm}$, follicle growth is stimulated by FSH secreted by the pituitary gland. Follicles develops by the rapid proliferation of granulosa and theca cells that contribute to the further enlargement of the antrum and the follicle itself. From a diameter of $8 \mathrm{~mm}$ onwards, the follicle develops mainly by the trophic stimulation of $\mathrm{LH}$, and eventually, after the LH surge, will be termed preovulatory follicles (Eppig et al., 1997).

At the end of its growth, the dominant follicle reaches a plateau phase of non-exponential growth with fewer cell divisions and slower diameter increase (Girard et al., 2015). Following the preovulatory gonadotropin surge, follicular cells initiate morphological, endocrine, and biochemical changes associated with luteinization process (Smith et al., 1994; Revelli et al., 2009). In monovulatory species, only one follicle continues its growth to become an ovulatory follicle, while the remaining antral follicles regress and undergo atresia (Hennet and Combelles, 2012).

For the follicle formation and its steady growth during the whole folliculogenesis process, the bidirectional communication within the follicle environment is essential for the complete development of the follicle as well as the oocyte. The crosstalk between the oocyte and somatic follicular cells and between the somatic follicular cells occurs through the interactions mediated by paracrine signaling factors, by gap junctions and, as recently described, by extracellular vesicles. The paracrine signaling occurs through the secretion of factors from the oocyte or from the somatic cells. The gap junctions are structures formed by connexins that allow the transport of molecules of low molecular weight $(<1 \mathrm{kDa})$ as ions, metabolites and amino acids between granulosa cells and cumulus cells, and between cumulus and oocyte cells. These junctions connect neighbor follicular cells or germ and somatic cell, at the bulk end of transzonal projections. The extracellular vesicles consist in a communication system mediated by vesicles secreted by cells. These vesicles, may have proteins, miRNAs and mRNAs as cargo, and are secrete and uptake by follicular cells (reviewed by Del Collado et al., 2018).

Hence, there are two physical barriers existing in the follicular environment, the $\mathrm{ZP}$ and the antrum. In both cases, cellular communication mechanism overcomes these barriers to maintain the exchange of messages via transzonal projections (TZPs) and extracellular vesicles (EVs; Fig. 2). These barriers, the communication mechanisms within, and the importance of such communication for the follicle and oocyte development are discussed in the following part of the review. 


\section{A}

Growing preantral follicle

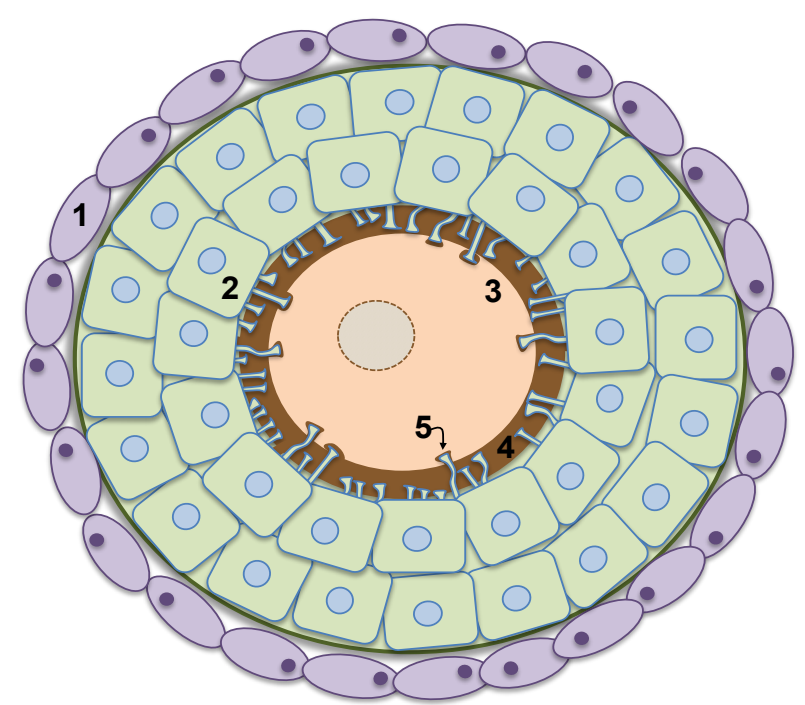

The zona pellucida

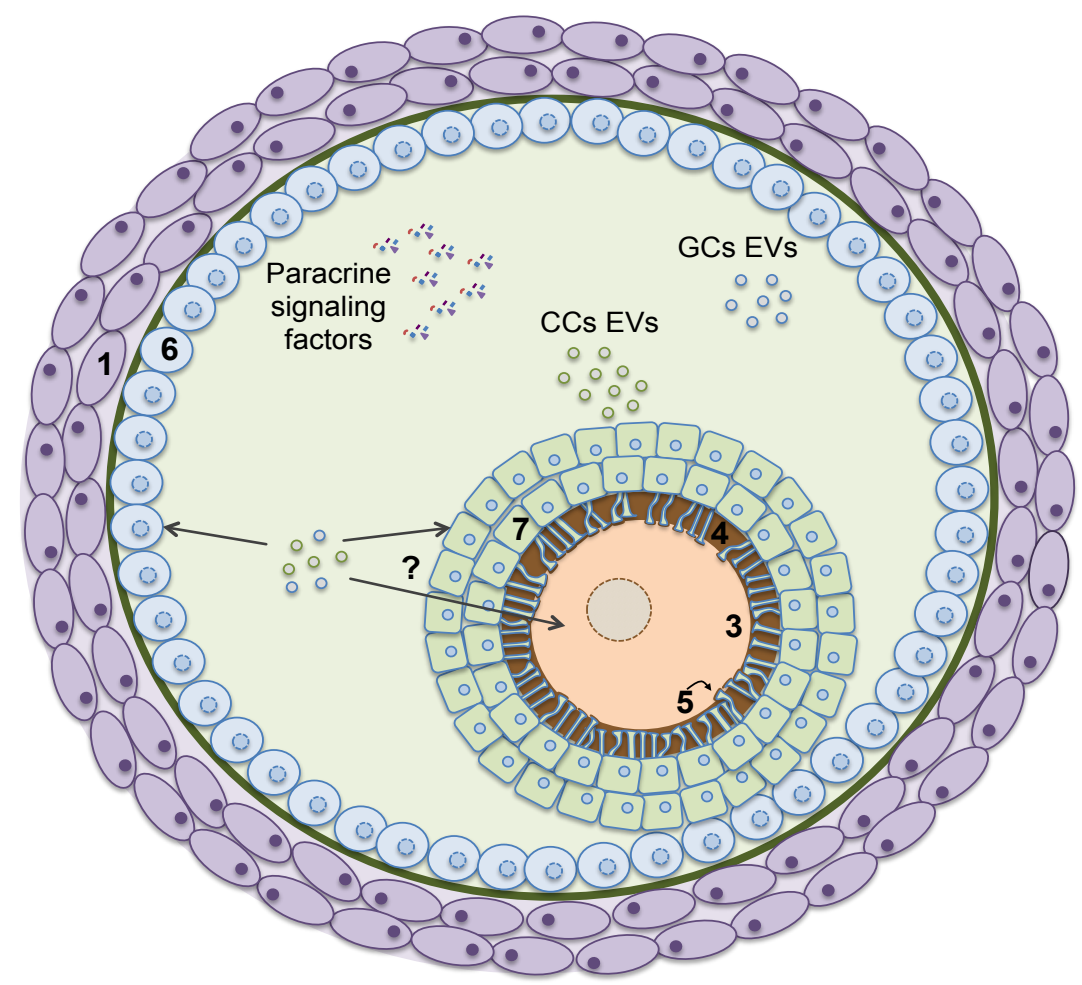

The antrum

Legend: $\mathbf{1}$ - Theca cells; $\mathbf{2}$ - Granulosa cells; $\mathbf{3}$ - Oocyte; $\mathbf{4}$ - Zona pellucida; 5 -Transzonal projections; $\mathbf{6}$ - Mural granulosa cells; 7 - Cumulus cells.

Figure 1. Physical barriers to cell-to-cell communication in the ovarian follicle are established during folliculogenesis. During preantral growth, zona pellucida, the first significant barrier between the oocyte and follicular cells, is formed. This barrier between the germ and somatic cells results from the deposition of glycoproteins by the oocyte. For continuous maintenance of a cytoplasmic bridge between germ and somatic cells, the oocyte stimulates the granulosa cells to generate specialized cytoplasmic filaments connecting both cells the transzonal projections (A). In antral growing follicles, a second significant barrier among follicular cells is formed - the antrum. Bilateral communication is maintained by paracrine signaling and extracellular vesicle traffic. Paracrine signaling of oocyte-secreted factors and transactivation of the EGF receptor by LH signaling drives follicle development and ovulation. Extracellular vesicles are secreted into the follicular fluid and are taken up by different cells types by a cargo delivery mechanism. The direct transfer of EVs-cargo from the follicular fluid to the oocyte remains elusive (B). CCs - cumulus cells; EVs - extracellular vesicles; GCs - granulosa cells; Theca - theca cells. 


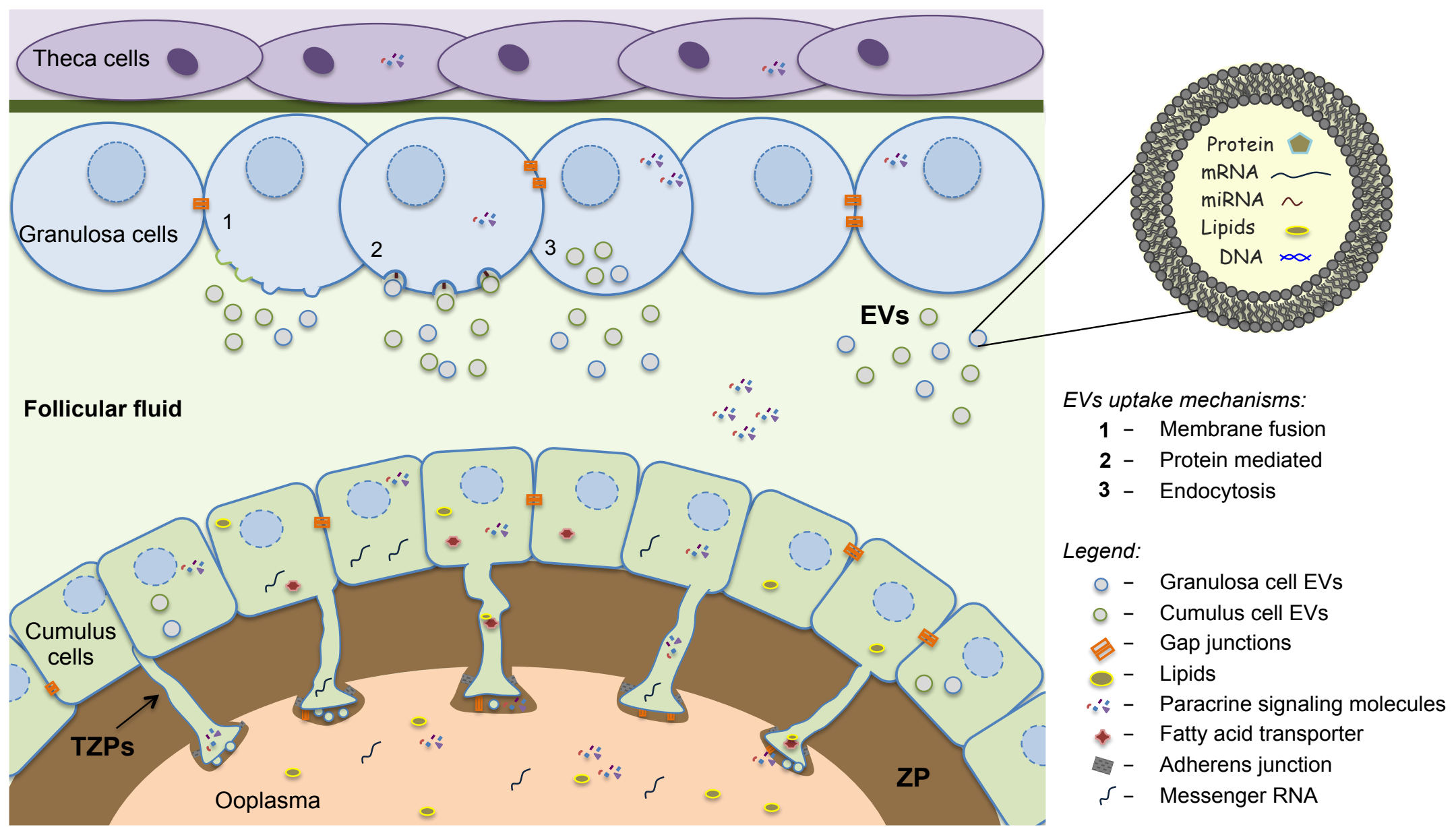

Figure 2. Bidirectional communication within the ovarian follicle microenvironment. The bidirectional crosstalk between cells that compose the follicle is associated with follicular development and acquisition of oocyte competence. Cellular crosstalk between germ-somatic cells and between somatic cells is mediated by the secretion of paracrine factors, by the communication through transzonal projections (TZPs) via gap junctions, and via extracellular vesicles (EVs) trafficking from the bulk end of TZPs to the oocyte, or trafficking into the follicular fluid. TZPs are specialized cytoplasmic projections that extend across zona pellucida (ZP) and allow the exchange of small molecules such as sugars, pyruvate, amino acids, and nucleotides, and large molecules such as mRNAs, lipids, and small organelles. Follicular fluid EVs are lipid bilayer vesicles loaded with proteins, mRNAs, microRNAs, lipids, and DNA and are taken up through endocytosis, protein recognition, and membrane fusion by distinct cell types within the ovarian follicle allowing communication with distant cells. 


\section{The first barrier}

\section{ZP formation and the germ-soma barrier}

The ZP is a relatively thick extracellular coat that surrounds all mammalian oocytes. It is formed in the preantral phase of follicular development during the formation of secondary follicles, when the oocytes are arrested in the late diplotene stage and undergoing active growth (Wassarman and Litscher, 2012). This porous extracellular coat is formed by three or four glycoproteins depending on the species (Bleil and Wassarman, 1980; reviewed by Gupta, 2015). The ZP has essential functions during oogenesis, fertilization, and pre-implantation development (Wassarman and Litscher, 2012). For example, during oocyte development, the $\mathrm{ZP}$ integrity is important to maintain the communication between the oocyte and the cumulus cells (Wang et al., 2019). During fertilization the ZP play fundamental roles, as the block of non-specific fertilization, the block of polyspermia (Wassarman, 1999; Florman and Ducibella, 2006). And during early embryo development the ZP permit that cleavage stage embryos move freely along the oviduct and protect the growing embryo until implantation (Gupta et al., 2015) so that the ZP presence is necessary for normal early development in uterus (Modliński, 1970).

As an oocyte increases in diameter, its ZP increases in thickness (Wassarman and Litscher, 2013) and separate the oocytes and the surrounding cumulus cells. Depending on the species, the $\mathrm{ZP}$ ranges in thickness from less than $1 \mathrm{~mm}$ to more than $25 \mathrm{~mm}$ (Keefe et al., 1997). Despite this physical separation, the oocytes and cumulus cells maintain contact by the formation of TZPs (Albertini et al., 2001; Eppig, 2018). TZPs mainly originate from the cumulus cells in the layer immediately adjacent to the oocyte, but they are also shown to arise from cumulus cells positioned in oocyte more distant layers (Jaffe and Egbert, 2017). Since the number of TZPs present in the ZP of a developing oocyte is quite high, it is likely that each somatic cell surrounding the oocyte emits multiple projections towards the oocyte. Also, some projections extend from a single point of origin at the granulosa cell membrane and subsequently dividing into several TZPs towards the ooplasm (El-Hayek et al., 2018).

There are two hypotheses for the formation of TZPs: by "stretching" or "pushing." In the "stretching" model, the adhesion sites between the oocyte and granulosa cells are already present before $\mathrm{ZP}$ formation and remain during the $\mathrm{ZP}$ deposition process, to become stretched cytoplasmic filaments called TZPs. The second hypothesis, known as "pushing," proposes that the TZPs are elaborated from the granulosa cells after the deposition of the $\mathrm{ZP}$ and grow towards the oocyte where they establish contact with their plasma membrane (Clarke, 2017).

The growing oocyte induces somatic cells to generate the TZPs (El-Hayek et al., 2018). Factors secreted by the oocyte, such as GDF9 and FSH, correlate with the development of TZPs. Recent studies show that GDF9 produced by the oocyte acts via the
SMAD signaling pathway to stimulate neighboring granulosa cells to generate TZP structures (El-Hayek et al., 2018). Besides that, recent functional studies verified that GDF9 maintains stable mRNAs that encode TZPs structural components (El-Hayek et al., 2018) and the absence of oocyte GDF9 leads to morphologically abnormal TZPs in mice (Dong et al., 1996; Carabatsos et al., 1998). FSH induces the retraction of TZPs, but the specific pathways by which this happens are still unclear (Combelles et al., 2004).

\section{Oocyte and soma interactions through TZPs}

The TZPs form concomitantly with the ZP and are specialized filopodia characterized as communication channels of approximately $2 \mathrm{um}$ in diameter without the fusion of membranes (Macaulay et al., 2014). These channels originate from the cytoplasmic filaments of actin or tubulin, and their function depends on the composition. TZPs formed by tubulin filaments are related to cell adhesion while actin TZPs are involved in cell communication, and the latter are prevalent in oocyte ZP (Li and Albertini, 2013).

These projections allow communication between the oocyte and somatic cells. As the TZPs are free-ended structures, the exchange of small molecules occurs at the bulk end of the projections by gap junctions and intermediate junctions (zonula adherenslike junctions) that keep the cytoplasmic membranes of both cells in close contact (Hyttel et al., 1997; Albertini and Barrett, 2004). Additionally, at the bulk end of TZPs, a cleft is formed between the plasma membrane of the TZP and the oolemma. Extracellular vesicles were identified at this cleft (Macaulay et al., 2014) and are involved in potential mechanisms by which cargo transfer occurs from somatic cells to oocyte.

Some molecules, such as mRNAs, lipids, pyruvate and cGMP, are shown to be transported through TZPs, suggesting the importance of these communication mechanisms between the oocyte and the surrounding cumulus cells. TZPs have distinct roles, for example: i) in mRNA accumulation, as evidenced by passage of polyadenylated transcripts (Macaulay et al., 2014; Macaulay et al., 2016), ii) in metabolic and nutritional cooperation, due to continuous exchange of small molecule ions, cyclic nucleotides, and amino acids (Thomas et al., 2004; Lodde et al., 2013), iii) and providing energy substrates such as pyruvate, lactate (Scantland et al., 2014), and other metabolites. Recent results show that TZPs also have a role in lipid transport from cumulus cells to oocyte. The TZPs lipid transport was proved by co-localization of fatty acid binding protein 3 (FABP3), a protein responsible for carrying lipids, with TZPs within zona pellucida and by the increase of oocyte lipid droplets dependent on the presence of TZPs, indicating that TZPs might be involved in the oocyte lipid accumulation during maturation (del Collado et al., 2017).

The communication through TZPs have fundamental role in the oocyte meiosis control and oocyte maturation, since the transport of essential molecules as cAMP, is mediated by TZPs from somatic 
cells to the oocyte (Eppig et al., 2005; Gilchrist et al., 2016). In vitro studies with bovine cumulus-oocyte complex revealed that the communication is maintained until the resumption of meiosis and onset of detachment within 9 h of maturation, and gradually decreases up to $22 \mathrm{~h}$, when it eventually comes to a stop (Macaulay et al., 2014). A recent study pointed out that inclusion of the pre-IVM phase with a combination of cAMP modulators, resulted in maintenance of the density of TZPs after $20 \mathrm{~h}$ of in vitro maturation, resulting in improvement in the cumulus-oocyte communication leading to enhanced oocyte developmental competence (Soto-Heras et al., 2019). In aging females, the ability of somatic cells to respond to oocyte signals is reduced, resulting in lower formation of TZPs. Consequently, the reduced oocyte-somatic cell communication is the presumed cause for the reduced fertility in aged females (El-Hayek et al., 2018).

Interestingly, most of the time the TZPs are not in contact with the oocyte, they subdivide and form gap junctions between each other (Baena and Terasaki, 2019), a sign that these projections also have other essential functions such as communication between somatic cells. The TZPs are involved in essential processes for oocyte and consequently, embryo development. Studies investigating the transport mechanisms present in TZPs and how the in vitro environment influences these projections are still ongoing. This knowledge will probably be helpful to prevent lipid accumulation, aging consequences, and to improve in vitro oocyte maturation, with broad implications for animal and human assisted reproduction technologies.

\section{The second barrier}

\section{Antrum formation and the cumulus-granulosa barrier}

The antral follicles are characterized by the formation of a cavity filled with the follicular fluid. The follicular fluid originates from two sources, the bloodstream of thecal capillaries present in the ovary cortical region, and the components secreted by follicular cell layers, especially the granulosa cells and the fluid production, which intensifies with the enlargement of the follicles (Rodgers and IrvingRodgers, 2010; Hennet and Combelles, 2012). The main hypothesis on follicular fluid formation suggests that an osmotic gradient is generated by granulosa cells production of hyaluronan and the chondroitin sulfate proteoglycan versican. This gradient generates influx of fluid derived from the thecal vasculature (Rodgers and Irving-Rodgers, 2010).

The follicular fluid contains a complex mixture of ions, proteins, metabolites, hormones, lipids, energy substrates, and reactive oxygen species (Leroy et al., 2004; Meeker et al., 2009; Ambekar et al., 2013). It serves as a source of regulatory molecules, such as gonadotrophins, steroids, growth factors, enzymes, proteoglycans, and lipoproteins (Revelli et al., 2009). This diverse array of molecules suggest that the follicular fluid is more than a reservoir and also supports intense metabolic activity, with substantial impact on follicular cells (Freitas et al., 2017) and oocyte. Roles of the follicular fluid were already reported, such as the participation in oocyte's acquisition of developmental competence (Fayezi et al., 2014; O’Gorman et al., 2013; Wallace et al., 2012) and in oocyte meiosis (Byskov et al., 1995; Mendoza et al., 2002). For example, hormone level in the follicular fluid, such as FSH (Suchanek et al., 1988), hCG (Ellsworth et al., 1984; Enien et al., 1998) and LH (Cha et al., 1986) have been reported to promote oocyte maturation and to increase chances of fertilization. The gonadotropins induce granulosa cells to secret hyaluronic acid (Mendoza et al., 2002) affecting oocyte development; they also act synergistically with estradiol (E2) enhancing cytoplasmatic maturation and controlling oocyte meiosis via cAMP secretion (Mendoza et al., 2002; Revelli et al., 2009). Another example is the fatty acids found in the follicular fluid that are incorporated by the oocyte and that have influence on oocyte maturation and quality. Excess of fatty acids were reported to negatively impact fertility outcomes (Shaaker et al., 2012).

The signaling mechanism for the formation of the antrum is not well understood; however, it was shown that FSH and type 1 insulin-like epidermal growth factors promote the formation of the antrum in cultured follicles in vitro (Gutierrez et al., 2000; Hillier, 2009). The growth of the antral follicles in bovines occurs in two distinct phases. The first is the slow phase where the follicles take approximately 30 days to advance from $0.3 \mathrm{~mm}$ in diameter to the stage of small antral follicles, which are about $3 \mathrm{~mm}$ in diameter. In this period of follicular growth, the oocyte reaches its final growth, approximately $110 \mu \mathrm{m}$ in diameter, which relates to the acquisition of competence for development (Fair et al., 1997; Rodriguez and Farin, 2004). The second phase is the active phase when small follicles, approximately $3 \mathrm{~mm}$ in diameter, take from five to seven days to become dominant follicles, more than $8 \mathrm{~mm}$ in diameter. This phase is followed by a variable period of dominance, culminating in the development of the preovulatory follicle and ovulation (Bleach et al., 2001; Mihm and Bleach, 2003).

Given that antrum formation separates follicular cells and gametes, the need to maintain the communication between these cells is accomplished mainly through paracrine signaling. An example of paracrine signaling is the oocyte-secreted factors (GDF9 and BMP15) that interact with molecules such as FSH, IGF1 and androgens to promote mural granulosa proliferation and cumulus cells differentiation (Gilchrist et al., 2004).

Other examples of critical paracrine factors are found in preovulatory follicle. The signaling cascade triggered by the pre-ovulatory LH peak propagate through the ovulatory follicle via paracrine factors and stimulates the release of epidermal growth factor (EGF) ligands from the mural granulosa cells, that move across the follicular fluid to reach the cumulus cells. In these target cells induce changes in gene expression that will decrease the cGMP concentration in the cumulus cells 
and consequently in the oocyte, resulting in cumulus cells expansion and meiosis resumption (Conti et al., 2012). The OSF also play vital roles regulating extracellular matrix stability, leading to ovulation (Gilchrist et al., 2004). Thus, this cascade is essential for the induction of gene expression required for follicle rupture, oocyte maturation and ovulation.

\section{A novel communication system in the antrum}

While paracrine signaling communication in follicular fluid have been described for many years, a novel communication mechanism, mediated by extracellular vesicles, has recently been described. Extracellular vesicles are phospholipid bilayer vesicles that transport biomolecules such as proteins, microRNAs, mRNAs, DNA, and lipids (Taylor and Gercel-Taylor, 2013; Di Pietro, 2016; Ávila et al., 2019). Their content varies and reflects the cell of origin (Akers et al., 2013). It was shown that the secretory cells actively select the number and the cargo of EVs depending on specific physiological and environmental conditions, such as diseases, nutritional status and stress (van Niel et al., 2018).

EVs are classified into microvesicles (MVs) and exosomes (Exos) according to their characteristics such as size, shape, membrane proteins, structural lipids, and their origin. The MVs are big with a diameter ranging from 500-1000 nm, have an irregular shape, and originate from the rupture of the cellular plasma membrane, which makes MVs a more heterogeneous population. On the other hand, the Exos have an approximate diameter of 50-100 nm (Crescitelli et al., 2013) and appear in electron microscopy as a cupshaped form, depending on the preparation method. Importantly, EVs originate from the late endosomes, also called multivesicular bodies and are released into the extracellular space by fusion of the multivesicular body membrane with the plasma cell membrane (Taylor and Gercel-Taylor, 2013).

There are three modes of interaction between the EV and their target cells; i) the first is through direct interaction between membrane proteins of the EV with receptors on the target cell membrane, ii) The second by membrane cleavage of the $\mathrm{EV}$ proteins by proteases present in the extracellular space, and the release of products which act on the receptors of the target cell, and iii) the third by direct fusion of the EV membranes with the cell membrane, releasing the EV content in the cell and incorporating proteins and receptors into the cell membrane (Mathivanan et al., 2010).

EVs are present in several body fluids and were first described in the follicular fluid a few years ago (da Silveira et al., 2012). Follicular cells secrete these vesicles into the follicular environment (Andrade et al., 2017a) and the EVs are taken up by the granulosa and cumulus cells, in in vivo and in vitro systems (da Silveira et al., 2012; Di Pietro, 2016). Additionally, the oocyte surrounding cumulus cells could provide an entry point to deliver to oocyte the molecules that cannot pass through gap junctions, such as RNAs, miRNAs, proteins and lipids (Macaulay et al., 2014;
Macaulay et al., 2016). Interestingly, in vitro studies showed that follicular fluid EVs alter transcript levels in oocytes (Dalanezi et al., 2017) and enhance oocyte competence to develop until the blastocyst stage (da Silveira et al., 2017).

The follicular fluid undergoes dynamic changes over late stages of folliculogenesis and its EVs content modify as consequence. As an example, the follicular fluid EVs from different size follicles have distinct concentrations and miRNA content (Navakanitworakul et al., 2016), and it has been described that they can differentially stimulate granulosa cells proliferation in vitro (Hung et al., 2017). Additionally, female age (Diez-Fraile et al., 2014; da Silveira et al., 2015a), and endocrine environment (da Silveira et al., 2015a) are important factors that can alter EVs content. Regarding female age, the miRNAs content of EVs from follicular fluid varies according to age. In old mares compare to young, a group of highly expressed miRNAs negatively modulates TGF- $\beta$, resulting in compromised maturation of oocytes (Da Silveira et al., 2015b). Also, the miR-23a, highly expressed in old mares (Da Silveira et al., 2015b), is correlated with human granulosa cells apoptosis pathway by inhibition of X-linked inhibitor of apoptosis protein (XIAP) and an increase in caspase 3 protein levels (Yang et al., 2012; Mobarak et al., 2019).

The bidirectional communication through EVs is associated with follicular development, oocyte growth, and quality, in humans and domestic animals (da Silveira et al., 2012; Sang et al., 2013; Sohel et al., 2013; Hung et al., 2015). During the maturation process, the EVs induce cumulus cell expansion and alter expression of genes related to the expansion process, when used as a supplement on cumulus-oocyte complexes (COCs) maturation medium (Hung et al., 2015). In another study, EVs stimulated granulosa cell proliferation by modulating Src, Pi3K/Akt and mitogenactivated protein kinase (MAPK) pathways, and interestingly, the EVs from small follicles were preferentially taken up by granulosa cells (Hung et al., 2017). Further, using EVs as supplements for embryo maturation in culture media, partially altered genes related to metabolism and development as well as miRNA and global DNA methylation and hydroxymethylation of bovine embryos produced in vitro (da Silveira et al., 2017). Another study observed a positive effect of follicular fluid EVs during in vitro maturation; they protected COCs from the harmful effects of heat shock stress (Rodrigues et al., 2019).

Although EVs carry different molecules, many studies show that the effect of EVs on cells are related to miRNAs and their regulatory effects, mainly because they are very stable and show resistance to degradation. The miRNAs in the follicular fluid EVs were associated with fertilization and embryo quality (Machtinger et al., 2017). Some studies, in humans and animals, have shown the role of miRNAs present in the follicular fluid, regulating follicular growth and development, cellular signaling, oocyte meiosis, and ovarian function (Martinez et al., 2018). EVs miRNAs modulate such important reproduction processes by the regulation of 
pathways as insulin, epidermal growth factor receptor (ErbB), MAPK, Wnt signaling, TGF- $\beta$ and PI3K-Akt signaling among others (da Silveira et al., 2012; Santonocito et al., 2014; Andrade et al., 2017b). Due to the importance of cellular communication in this environment and the immense potential of EVs, efforts are dedicated to better understand its functions and importance during oocyte maturation and early embryo development in vitro.

\section{Conclusions and perspectives}

Normal oocyte development depends on a finely regulated, constant, and reciprocal cell-to-cell communication between the follicle components. The crosstalk may occur by paracrine signaling and exchange of small molecules via gap-junctions; these are wellstudied mechanisms. However, novel mechanisms of communication in the follicle microenvironment have been recently identified. These mechanisms allow the exchange of large molecules, such as nucleic acids, proteins, and lipids between follicular compartments, and are mediated by the trafficking of vesicles from the bulk-end of TZPs to the oolemma, or by the transit of EVs in the follicular fluid.

The importance of these novel communication mechanisms is exemplified by circumstances for which association with communication mediated by TZP or EVs has already been demonstrated, such as the accumulation of maternal transcripts in the oocyte, the acquisition of oocyte competence, and the decline in oocyte developmental potential associated with aging. Moreover, there is increasing evidence that assisted reproductive technologies disturbs the intrafollicular interactions, but their short and long-term effects are yet to be studied.

Studies in this field are limited, and in addition to the lack of knowledge about the effects of disrupting such communication mechanisms, there are plenty of unanswered questions in the subject area. Among other questions, it is unknown how the passage of molecules into the oocytes is regulated, and whether EVs in the follicular fluid can directly or indirectly modulate the oocyte. A thorough understanding of the biology of TZPs and EVs-mediated communication will potentiate the advancement of assisted reproductive technologies. These possibilities include modulation of the function of TZPs, regulation of EVs-cargo, and its use in in vitro culture conditions.

\section{Author contributions}

GMA: Conceptualization, Data curation, Investigation, Visualization, Writing - original draft, Writing - review \& editing; MC: Conceptualization, Data curation, Investigation, Writing - original draft, Writing review \& editing; FVM: Funding acquisition, Resources, Writing - review \& editing; JCS: Conceptualization, Funding acquisition, Methodology, Resources, Writing review \& editing; FP: Conceptualization, Formal Analysis, Funding acquisition, Methodology, Project administration, Resources, Supervision, Writing review\& editing.

\section{Conflict of interest}

The authors declare that they have no competing interests.

Acknowledgments and Funding disclosure statement

The authors would like to thank Sao Paulo Research Foundation (FAPESP) - grants (GMA) 2018/01431-9; (MDC) 2017/19825-0; (FMV) 2013/08135-2; (JCS) 2014/22887-0; (FP) 2018/131556 ; and National Council for Scientific and Technological Development (CNPq) - grant (FP) 306349/2017-5.

\section{References}

Akers JC, Gonda D, Kim R, Carter BS, Chen CC. 2013. Biogenesis of extracellular vesicles (EV): exosomes, microvesicles, retrovirus-like vesicles, and apoptotic bodies. J Neurooncol, 113:1-11.

Albertini DF, Barrett SL. 2004. The developmental origins of mammalian oocyte polarity. Semin Cell Dev Biol, 15, 599-606.

Albertini DF, Combelles CMH, Benecchi E, Carabatsos MJ. 2001. Cellular basis for paracrine regulation of ovarian follicle development. Reproduction, 121:647-653.

Ambekar AS, Nirujogi RS, Srikanth SM, Chavan S, Kelkar DS, Hinduja I, Zaveri K, Prasad TSK, Harsha HC, Pandey A, Mukherjee S. 2013. Proteomic analysis of human follicular fluid: A new perspective towards understanding folliculogenesis. $J$ Proteomics, 87:68-77.

Andrade G, Meirelles F, Perecin F, Silveira J. 2017a. Cellular and extracellular vesicular origins of miRNAs within the bovine ovarian follicle. Reprod Domest Anim, 52(6):1036-1045.

Andrade GM, da Silveira JC, Perrini C, Del Collado M, Gebremedhn S, Tesfaye D, Meirelles FV, Perecin F. 2017b. The role of the PI3K-Akt signaling pathway in the developmental competence of bovine oocytes. Plos One, 12.

Ávila ACFM, Andrade GM, Bridi A, Gimenes LU, Meirelles FV, Perecin F, da Silveira JC. 2019. Extracellular vesicles and its advances in female reproduction. Anim Reprod,16:31-38.

Baena V, Terasaki M. 2019. Three-dimensional organization of transzonal projections and other cytoplasmic extensions in the mouse ovarian follicle. Sci Rep, 9(1):1262.

Bleach ECL, Glencross RG, Feist SA, Groome NP, Knight PG. 2001. Plasma inhibin A in heifers: Relationship with follicle dynamics, gonadotropins, and steroids during the estrous cycle and after treatment with bovine follicular fluid. Biol Reprod, 64:743-752.

Bleil JD, Wassarman PM. 1980. Structure and function of the zona pellucida: identification and characterization of the proteins of the mouse oocyte's zona pellucida. Dev Biol, 76:185-202.

BrawTal R, Yossefi S. 1997. Studies in vivo and in ivtro on the initiation of follicle growth in the bovine ovary. J Reprod Fertil, 109:165-171. 
Buehr M. 1997. The primordial germ cells of mammals: Some current perspectives. Exp Cell Res, 232:194-207.

Byskov AG, Andersen CY, Nordholm L, Thogersen H, Xia GL, Wassmann O, Andersen JV, Guddal E, Roed T. 1995. Chemical-structure of sterols that activate oocyte meiosis. Nature, 374:559-562.

Carabatsos MJ, Elvin J, Matzuk MM, Albertini DF. 1998. Characterization of oocyte and follicle development in growth differentiation factor-9-deficient mice. Dev Biol, 204:373-384.

Cha K-Y, Barnes RB, Marrs RP, Lobo RA. 1986. Correlation of the bioactivity of luteinizing hormone in follicular fluid with oocyte maturity in the spontaneous cycle. Fertil Steril, 45:338-341.

Chakraborty P, Roy SK. 2017. Stimulation of primordial follicle assembly by estradiol-17 beta requires the action of bone morphogenetic protein-2 (BMP2). Sci Rep, 7(1):15581.

Clarke HJ. 2017. Regulation of germ cell development by intercellular signaling in the mammalian ovarian follicle. Wiley Interdisciplinary Reviews: Dev Biol, 7:e294. Doi: 10.1002/wdev.294.

Clarke HJ. 2018. History, origin, and function of transzonal projections: the bridges of communication between the oocyte and its environment. Anim Reprod, 15:215-223.

Combelles CMH, Carabatsos MJ, Kumar TR, Matzuk MM, Albertini DF. 2004. Hormonal control of somatic cell oocyte interactions during ovarian follicle development. Mol Reprod Dev, 69:347-355.

Conti M, Hsieh M, Zamah AM, Oh JS. 2012. Novel signaling mechanisms in the ovary during oocyte maturation and ovulation. Mol Cell Endocrinol, 356:6573.

Crescitelli R, Lässer C, Szabo TG, Kittel A, Eldh M, Dianzani I, Buzás EI, Lötvall J. 2013. Distinct RNA profiles in subpopulations of extracellular vesicles: apoptotic bodies, microvesicles and exosomes. $J$ Extracell Vesicles, 2: eCollection 2013. Doi: 10.3402/jev.v2i0.20677.

da Silveira JC, Andrade GM, del Collado $M$, Sampaio RV, Sangalli JR, Silva LA, Pinaffi FVL, Jardim IB, Cesar MC, Nogueira MFG, Cesar ASM, Coutinho LL, Pereira RW, Perecin F, Meirelles FV. 2017. Supplementation with small-extracellular vesicles from ovarian follicular fluid during in ivtro production modulates bovine embryo development. Plos One, 12(6):e0179451. Doi: 10.1371/journal.pone.0179451.

da Silveira JC, de Andrade GM, Nogueira MFG, Meirelles FV, Perecin F. 2015a. Involvement of mirnas and cell-secreted vesicles in mammalian ovarian antral follicle development. Reprod Sci, 22:1474-1483.

da Silveira JC, Veeramachaneni DNR, Winger QA, Carnevale EM, Bouma GJ. 2012. Cell-Secreted Vesicles in Equine Ovarian Follicular Fluid Contain miRNAs and Proteins: A Possible New Form of Cell Communication Within the Ovarian Follicle. Biol Reprod, 86(3):71. Doi: 10.1095/biolreprod.111.093252. da Silveira JC, Winger QA, Bouma GJ, Carnevale EM. 2015b. Effects of age on follicular fluid exosomal microRNAs and granulosa cell transforming growth factor-beta signalling during follicle development in the mare. Reprod Fertil Dev, 27:897-905.

Dalanezi F, Destro F, Ferrazza R, García HM, Franchi F, Fontes P, Castilho A, Sartori R, Ferreira J. 2017. 183 Gene expression of in ivtro-maturated oocytes can be modulated by follicle exosomes from cows kept under thermoneutral or heat stress conditions. Reprod Fertil Dev, 29:200-200.

del Collado M, Andrade GM, Meirelles FV, da Silveira JC, Perecin F. 2018. Contributions from the ovarian follicular environment to oocyte function. Anim Reprod, 15:261-270.

del Collado M, da Silveira JC, Sangalli JR, Andrade GM, Sousa L, Silva LA, Meirelles FV, Perecin F. 2017. Fatty acid binding protein 3 and transzonal projections are involved in lipid accumulation during in ivtro maturation of bovine oocytes. Sci Rep, 7:2645. Doi:10.1038/s41598-017-02467-9

Di Pietro C. 2016. Exosome-mediated communication in the ovarian follicle. Journal of Assisted Reproduction and Genetics, 33:303-311.

Diez-Fraile A, Lammens T, Tilleman K, Witkowski W, Verhasselt B, De Sutter P, Benoit Y, Espeel M, D'Herde K. 2014. Age-associated differential microRNA levels in human follicular fluid reveal pathways potentially determining fertility and success of in ivtro fertilization. Hum Fertil, 17:90-98.

Dong JW, Albertini DF, Nishimori K, Kumar TR, Lu NF, Matzuk MM. 1996. Growth differentiation factor-9 is required during early ovarian folliculogenesis. Nature, 383:531-535.

Dvořák M, Tesařík J. 1980. Ultrastructure of human ovarian follicles, Biology of the Ovary, Springer, pp.121-137.

El-Hayek S, Clarke HJ. 2015. Follicle-stimulating hormone increases gap junctional communication between somatic and germ-line follicular compartments during murine oogenesis. Biol Reprod, 93(2):47. Doi: 10.1095/biolreprod.115.129569.

El-Hayek S, Yang Q, Abbassi L, FitzHarris G, Clarke HJ. 2018. Mammalian oocytes locally remodel follicular architecture to provide the foundation for germline-soma communication. Curr Biol, 28(7):11241131.

Ellsworth L, Balmaceda J, Schenken RS, Silverman A, Prihoda T, Asch R. 1984. Human chorionic gonadotropin and steroid concentrations in human follicular fluid in relation to follicle size and oocyte maturity in stimulated ovarian cycles. Acta Eur Fertil, 15:343-346.

Enien W, Chantler E, Seif M, Elstein M. 1998. Human ovarian granulosa cells and follicular fluid indices: the relationship to oocyte maturity and fertilization in ivtro. Human Reprod, 13:1303-1306.

Eppig JJ. 2001. Oocyte control of ovarian follicular development and function in mammals. Reproduction, 122:829-838.

Eppig JJ. 2018. Reproduction: oocytes call, granulosa cells connect. Curr Biol, 28:R354-R356.

Eppig JJ, Pendola FL, Wigglesworth K, Pendola JK. 2005. Mouse oocytes regulate metabolic cooperativity between granulosa cells and oocytes: Amino acid 
transport. Biol Reprod, 73:351-357.

Eppig JJ, Wigglesworth K, Pendola F, Hirao Y, 1997. Murine oocytes suppress expression of luteinizing hormone receptor messenger ribonucleic acid by granulosa cells. Biol Reprod, 56:976-984.

Erickson B. 1966. Development and senescence of the postnatal bovine ovary. J Anim Sci, 25:800-805.

Erickson GF, Shimasaki S. 2001. The physiology of folliculogenesis: the role of novel growth factors. Fertil Steril, 76:943-949.

Fair T, Hulshof SCJ, Hyttel P, Greve T, Boland M. 1997. Oocyte ultrastructure in bovine primordial to early tertiary follicles. Anat Embryol, 195:327-336.

Fayezi S, Darabi M, Nouri M, Rahimipour A, Mehdizadeh A. 2014. Analysis of follicular fluid total phospholipids in women undergoing in-vitro fertilisation. J Obstet Gynaecol, 34:259-262. Florman HM, Ducibella T. 2006. Fertilization in mammals. Knobil and Neill's physiology of Reproduction, 3:55112.

Fortune JE. 1994. Ovarian follicular-growth and development in mammals. Biol Reprod, 50:225-232.

Freitas C, Neto AC, Matos L, Silva E, Ribeiro A, Silva-Carvalho JL, Almeida H. 2017. Follicular Fluid redox involvement for ovarian follicle growth. J Ovarian Res, 10(1):44. Doi: 10.1186/s13048-017-0342-3.

Gilchrist RB, Luciano AM, Richani D, Zeng HT, Wang $X$, De Vos M, Sugimura S, Smitz J, Richard FJ, Thompson JG. 2016. Oocyte maturation and quality: role of cyclic nucleotides. Reproduction, 152:R143-R157.

Gilchrist RB, Ritter LJ, Armstrong DT. 2004. Oocyte-somatic cell interactions during follicle development in mammals. Anim Reprod Sci, 82-3:431446.

Girard A, Dufort I, Douville G, Sirard MA. 2015. Global gene expression in granulosa cells of growing, plateau and atretic dominant follicles in cattle. Reprod Biol Endocrinol, 13:17. Doi: 10.1186/s12958-0150010-7.

Guo J, Shi LY, Gong XH, Jiang MJ, Yin YX, Zhang XY, Yin H, Li H, Emori C, Sugiura K, Eppig JJ, Su YQ. 2016. Oocyte-dependent activation of MTOR in cumulus cells controls the development and survival of cumulus-oocyte complexes. J Cell Sci, 129:3091-3103.

Gupta SK. 2015. Role of zona pellucida glycoproteins during fertilization in humans. J Reprod Immunol, 108:90-97.

Gutierrez CG, Ralph JH, Telfer EE, Wilmut I, Webb R. 2000. Growth and antrum formation of bovine preantral follicles in long-term culture in ivtro. Biol Reprod, 62:1322-1328.

Hennet ML, Combelles CMH. 2012. The antral follicle: a microenvironment for oocyte differentiation. Int J Dev Biol, 56:819-831.

Hillier SG. 2009. Paracrine support of ovarian stimulation. Mol Hum Reprod, 15:843-850.

Hung W-T, Hong X, Christenson LK, McGinnis LK. 2015. Extracellular vesicles from bovine follicular fluid support cumulus expansion. Biol Reprod, 93(5):117. Doi: 10.1095/biolreprod.115.13297.

Hung W-T, Navakanitworakul R, Khan T, Zhang P,
Davis JS, McGinnis LK, Christenson LK. 2017. Stage-specific follicular extracellular vesicle uptake and regulation of bovine granulosa cell proliferation. Biol Reprod, 97(4):644-655.

Hyttel P, Fair T, Callesen H, Greve T. 1997. Oocyte growth, capacitation and final maturation in cattle. Theriogenology, 47:23-32.

Jaffe LA, Egbert JR. 2017. Regulation of mammalian oocyte meiosis by intercellular communication within the ovarian follicle. Ann Rev Physiol, 79:237-260.

Keefe D, Tran P, Pellegrini C, Oldenbourg R. 1997. Polarized light microscopy and digital image processing identify a multilaminar structure of the hamster zona pellucida. Hum Reprod, 12:1250-1252.

Kerr JB, Myers M, Anderson RA. 2013. The dynamics of the primordial follicle reserve. Reproduction, 146:R205-R215.

Knight PG, Glister, C, 2006. TGF-beta superfamily members and ovarian follicle development. Reproduction, 132:191-206.

Leroy J, Vanholder T, Delanghe JR, Opsomer G, Van Soom A, Bols PEJ, de Kruif A. 2004. Metabolite and ionic composition of follicular fluid from differentsized follicles and their relationship to serum concentrations in dairy cows. Anim Reprod Sci, 80:201211.

Li R, Albertini DF. 2013. The road to maturation: somatic cell interaction and self-organization of the mammalian oocyte. Nat Rev Mol Cell Biol, 14:141-152. Lodde V, Franciosi F, Tessaro I, Modina SC, Luciano AM. 2013. Role of gap junction-mediated communications in regulating large-scale chromatin configuration remodeling and embryonic developmental competence acquisition in fully grown bovine oocyte. $J$ Assist Reprod Genet, 30:1219-1226.

Macaulay AD, Gilbert I, Caballero J, Barreto R, Fournier E, Tossou P, Sirard MA, Clarke HJ, Khandjian EW, Richard FJ, Hyttel P, Robert C. 2014. The gametic synapse: rna transfer to the bovine oocyte. Biol Reprod, 91(4):90. doi: 10.1095/biolreprod.114.119867.

Macaulay AD, Gilbert I, Scantland S, Fournier E, Ashkar F, Bastien A, Saadi HAS, Gagne D, Sirard MA, Khandjian EW, Richard FJ, Hyttel P, Robert C. 2016. Cumulus cell transcripts transit to the bovine oocyte in preparation for maturation. Biol Reprod, 94(1):16. Doi: 10.1095/biolreprod.114.127571.

Machtinger R, Rodosthenous RS, Adir M, Mansour A, Racowsky C, Baccarelli AA, Hauser R. 2017. Extracellular microRNAs in follicular fluid and their potential association with oocyte fertilization and embryo quality: an exploratory study. J Assist Reprod Genet, 34:525-533.

Martinez RM, Liang LM, Racowsky C, Dioni L, Mansur A, Adir M, Bollati V, Baccarelli AA, Hauser R, Machtinger R. 2018. Extracellular microRNAs profile in human follicular fluid and IVF outcomes.Sci Rep, 8(1):17036. Doi: 10.1038/s41598-018-35379-3.

Mathivanan S, Ji H, Simpson RJ. 2010. Exosomes: Extracellular organelles important in intercellular communication. J Proteomics,73:1907-1920.

Matzuk MM, Burns KH, Viveiros MM, Eppig JJ. 
2002. Intercellular communication in the mammalian ovary: Oocytes carry the conversation. Science, 296:2178-2180.

McLaughlin M, Bromfield JJ, Albertini DF, Telfer EE. 2010. Activin promotes follicular integrity and oogenesis in cultured pre-antral bovine follicles. Mol Hum Reprod, 16:644-653.

Meeker JD, Missmer SA, Altshul L, Vitonis AF, Ryan L, Cramer DW, Hauser R. 2009. Serum and follicular fluid organochlorine concentrations among women undergoing assisted reproduction technologies. Environ Health, 8:32. Doi: 10.1186/1476-069X-8-32.

Mendoza C, Ruiz-Requena E, Ortega E, Cremades N, Martinez F, Bernabeu R, Greco E, Tesarik J. 2002. Follicular fluid markers of oocyte developmental potential. Hum Reprod, 17:1017-1022.

Mihm A, Bleach ECL. 2003. Endocrine regulation of ovarian antral follicle development in cattle. Anim Reprod Sci, 78:217-237.

Mobarak H, Heidarpour M, Lolicato F, Nouri M, Rahbarghazi R, Mahdipour M. 2019. Physiological impact of extracellular vesicles on female reproductive system; highlights to possible restorative effects on female age-related fertility. Biofactors, 45(3):293-303.

Modliński JA. 1970. The role of the zona pellucida in the development of mouse eggs in vivo. J Embryol Exp Morphol, 23:539-547.

Monniaux D. 2016. Driving folliculogenesis by the oocyte-somatic cell dialog: Lessons from genetic models. Theriogenology, 86:41-53.

Motta PM, Makabe S, Nottola SA. 1997. The ultrastructure of human reproduction .1. The natural history of the female germ cell: origin, migration and differentiation inside the developing ovary. Hum Reprod Update, 3:281-295.

Navakanitworakul R, Hung WT, Gunewardena S, Davis JS, Chotigeat W, Christenson LK. 2016. characterization and small RNA content of extracellular vesicles in follicular fluid of developing bovine antral follicles. Sci Rep, 6:25486. Doi: 10.1038/srep25486.

O'Gorman A, Wallace M, Cottell E, Gibney MJ, McAuliffe FM, Wingfield M, Brennan L. 2013. Metabolic profiling of human follicular fluid identifies potential biomarkers of oocyte developmental competence. Reproduction, 146:389-395.

Paulini F, Silva RC, Rolo J, Lucci CM. 2014. Ultrastructural changes in oocytes during folliculogenesis in domestic mammals. J Ovarian Res, 7:102. Doi: 10.1186/s13048-014-0102-6.

Pepling ME. 2012. Follicular assembly: mechanisms of action. Reproduction, 143:139-149.

Revelli A, Delle Piane L, Casano S, Molinari E, Massobrio M, Rinaudo P. 2009. Follicular fluid content and oocyte quality: from single biochemical markers to metabolomics. Reprod Biol Endocrinol, 7:40. Doi: 10.1186/1477-7827-7-40.

Rodgers RJ, Irving-Rodgers HF. 2010. Formation of the ovarian follicular antrum and follicular fluid. Biol Reprod, 82:1021-1029.

Rodrigues TA, Tuna KM, Alli AA, Tribulo P, Hansen P, Koh J, Paula-Lopes F. 2019. Follicular fluid exosomes act on the bovine oocyte to improve oocyte competence to support development and survival to heat shock. Reprod Fertil Dev, 31(5):888-897. Doi: 10.1071/RD18450.

Rodriguez KF, Farin CE. 2004. Developmental capacity of bovine cumulus oocyte complexes after transcriptional inhibition of germinal vesicle breakdown. Theriogenology, 61:1499-1511.

Russe I. 1983. Oogenesis in cattle and sheep. Bibl Anat, 24:77-92.

Sanfins A, Rodrigues P, Albertini DF. 2018. GDF-9 and BMP-15 direct the follicle symphony. J Assist Reprod Genet, 35:1741-1750.

Sang Q, Yao ZY, Wang H, Feng RZ, Wang HJ, Zhao XZ, Xing QH, Jin L, He L, Wu LQ, Wang L. 2013. Identification of microRNAs in human follicular fluid: characterization of microRNAs that govern steroidogenesis in ivtro and are associated with polycystic ovary syndrome in vivo. J Clin Endocrinol Metab, 98:3068-3079.

Santonocito M, Vento M, Guglielmino MR, Battaglia R, Wahlgren J, Ragusa $M$, Barbagallo $D$, Borzi $P$, Rizzari S, Maugeri M, Scollo P, Tatone C, Valadi H, Purrello M, Di Pietro C. 2014. Molecular characterization of exosomes and their microRNA cargo in human follicular fluid: bioinformatic analysis reveals that exosomal microRNAs control pathways involved in follicular maturation. Fertil Steril, 102:1751-U1590.

Scantland S, Tessaro I, Macabelli CH, Macaulay AD, Cagnone G, Fournier E, Luciano AM, Robert C. 2014. The adenosine salvage pathway as an alternative to mitochondrial production of ATP in maturing mammalian oocytes. Biol Reprod, 91(3):75. Doi: 10.1095/biolreprod.114.120931.

Shaaker M, Rahimipour A, Nouri M, Khanaki K, Darabi M, Farzadi L, Shahnazi V, Mehdizadeh A. 2012. Fatty acid composition of human follicular fluid phospholipids and fertilization rate in assisted reproductive techniques. Iran Biomed J, 16:162-168.

Smith MF, McIntush EW, Smith GW, 1994. Mechanisms Associated With Corpus-Luteum Development. J Anim Sci, 72:1857-1872.

Sohel MMH, Hoelker M, Noferesti SS, SalilewWondim D, Tholen E, Looft C, Rings F, Uddin MJ, Spencer TE, Schellander K, Tesfaye D. 2013. Exosomal and non-exosomal transport of extra-cellular micrornas in follicular fluid: implications for bovine oocyte developmental competence. Plos One, 8(11):e78505. Doi: 10.1371/journal.pone.0078505.

Soto-Heras S, Paramio M-T, Thompson JG. 2019. Effect of pre-maturation with C-type natriuretic peptide and 3-isobutyl-1-methylxanthine on cumulus-oocyte communication and oocyte developmental competence in cattle. Anim Reprod Sci, 202:49-57.

Suchanek E, Simunic V, Macas E, Kopjar B, Grizelj V. 1988. Prostaglandin F2 $\alpha$, progesterone and estradiol concentrations in human follicular fluid and their relation to success of in ivtro fertilization. Eur J Obstet Gynecol Reprod Biol, 28:331-339.

Sun YC, Sun XF, Dyce PW, Shen W, Chen H. 2017. The role of germ cell loss during primordial follicle assembly: a review of current advances. Int J Biol Sci, 13:449-457. 
Taylor DD, Gercel-Taylor C. 2013. The origin, function, and diagnostic potential of RNA within extracellular vesicles present in human biological fluids. Front Genet, 4:142. Doi: 10.3389/fgene.2013.00142.

Thomas RE, Armstrong DT, Gilchrist RB. 2004. Bovine cumulus cell-oocyte gap junctional communication during in ivtro maturation in response to manipulation of cell-specific cyclic adenosine 3 ',5 'monophosophate levels. Biol Reprod, 70:548-556.

Tilly JL. 2001. Commuting the death sentence: How oocytes strive to survive. Nat Rev Mol Cell Biol, 2:838848.

van Niel G, D'Angelo G, Raposo G. 2018. Shedding light on the cell biology of extracellular vesicles. Nat Rev Mol Cell Biol, 19:213-228.

vandenHurk R, Bevers MM, Beckers JF. 1997. Invivo and in-vitro development of preantral follicles. Theriogenology, 47:73-82.

Wallace M, Cottell E, Gibney MJ, McAuliffe FM, Wingfield M, Brennan L. 2012. An investigation into the relationship between the metabolic profile of follicular fluid, oocyte developmental potential, and implantation outcome. Fertil Steril, 97(5):10781084.e1-8. Doi: 10.1016/j.fertnstert.2012.01.122.

Wang C, Roy SK. 2007. Development of primordial follicles in the hamster: Role of estradiol-17 beta. Endocrinology, 148:1707-1716.

Wang Y, Lv C, Huang H-L, Zeng M-H, Yi D-J, Tan H-J, Peng T-L, Yu W-X, Deng H-W, Xiao H-M. 2019. Influence of mouse defective zona pellucida in folliculogenesis on apoptosis of granulosa cells and developmental competence of oocytes. Biol Reprod. Doi: 10.1093/biolre/ioz093.

Wang YY, Sun YC, Sun XF, Cheng SF, Li B, Zhang XF, De Felici M, Shen W. 2017. Starvation at birth impairs germ cell cyst breakdown and increases autophagy and apoptosis in mouse oocytes. Cell Death Dis, 8(2):e2613. Doi: 10.1038/cddis.2017.3.

Wassarman PM. 1999. Mammalian fertilization: molecular aspects of gamete adhesion, exocytosis, and fusion. Cell, 96:175-183.

Wassarman PM, Litscher ES. 2012. Influence of the zona pellucida of the mouse egg on folliculogenesis and fertility. Int J Dev Biol, 56(10-12):833-9. Doi: 10.1387/ijdb.120136pw.

Wassarman PM, Litscher ES. 2013. Biogenesis of the Mouse Egg's Extracellular Coat, the Zona Pellucida. Gametogenesis, 102:243-266.

Wigglesworth K, Lee KB, Emori C, Sugiura K, Eppig JJ. 2015. Transcriptomic diversification of developing cumulus and mural granulosa cells in mouse ovarian follicles. Biol Reprod, 92(1):23. Doi: 10.1095/biolreprod.114.121756.

Yang XK, Zhou Y, Peng S, Wu L, Lin HY, Wang SY, Wang HM. 2012. Differentially expressed plasma microRNAs in premature ovarian failure patients and the potential regulatory function of mir-23a in granulosa cell apoptosis. Reproduction, 144:235-244.

Zuckerman S. 1951. The number of oocytes in the mature ovary. Recent Prog Horm Res, 6:63-109. 